\title{
More than a statistic
}

Cite as: CMAJ 2020 April 6;192:E378-9. doi: 10.1503/cmaj.191349

pretended I was the only person in the room, avoiding the intake nurse's attempts to make eye contact. I read the pharmaceutical posters on the walls. I stared at the medical equipment littered around the room. I occupied myself, nervously fidgeting with my hands - hands that had become clammy in anticipation of this clinic visit, from the judgment I presumed I would receive. I was there to get tested for sexually transmitted infections (STIs) and, being gay, I was uneasy about starting that conversation with a doctor I did not know. Talking about sex can be awkward, especially when you don't fit the norm. I am a medical student, and although clinics and blood tests have become commonplace in my life, the familiarity I should've felt in that office was nowhere to be found.

"Do your sexual partners or partner have male genitals, female genitals, or both?"

I looked up, surprised yet grateful for how nonchalantly the nurse asked about my sexual history. Often it can be easier for those of us in health care to avoid taboo topics, or to quickly (and awkwardly) ask patients questions along the lines of "Are you gay or straight? Is your partner a man or woman?" These simple words are loaded with assumptions, judgments and a fundamental lack of appreciation for sexual and gender diversity. But here, no assumptions were being made regarding my sexuality or that of my partner. No judgment accompanied the nurse's questions. No barriers were constructed before I saw the doctor. It seemed there was no reason to be nervous.

The sweat on my palms began to evaporate, and I was quickly put at ease.

"Penetrated or penetrative?" the doctor awkwardly began. Before I could process what was being asked, I was barraged with more questions: "You're in a high-risk

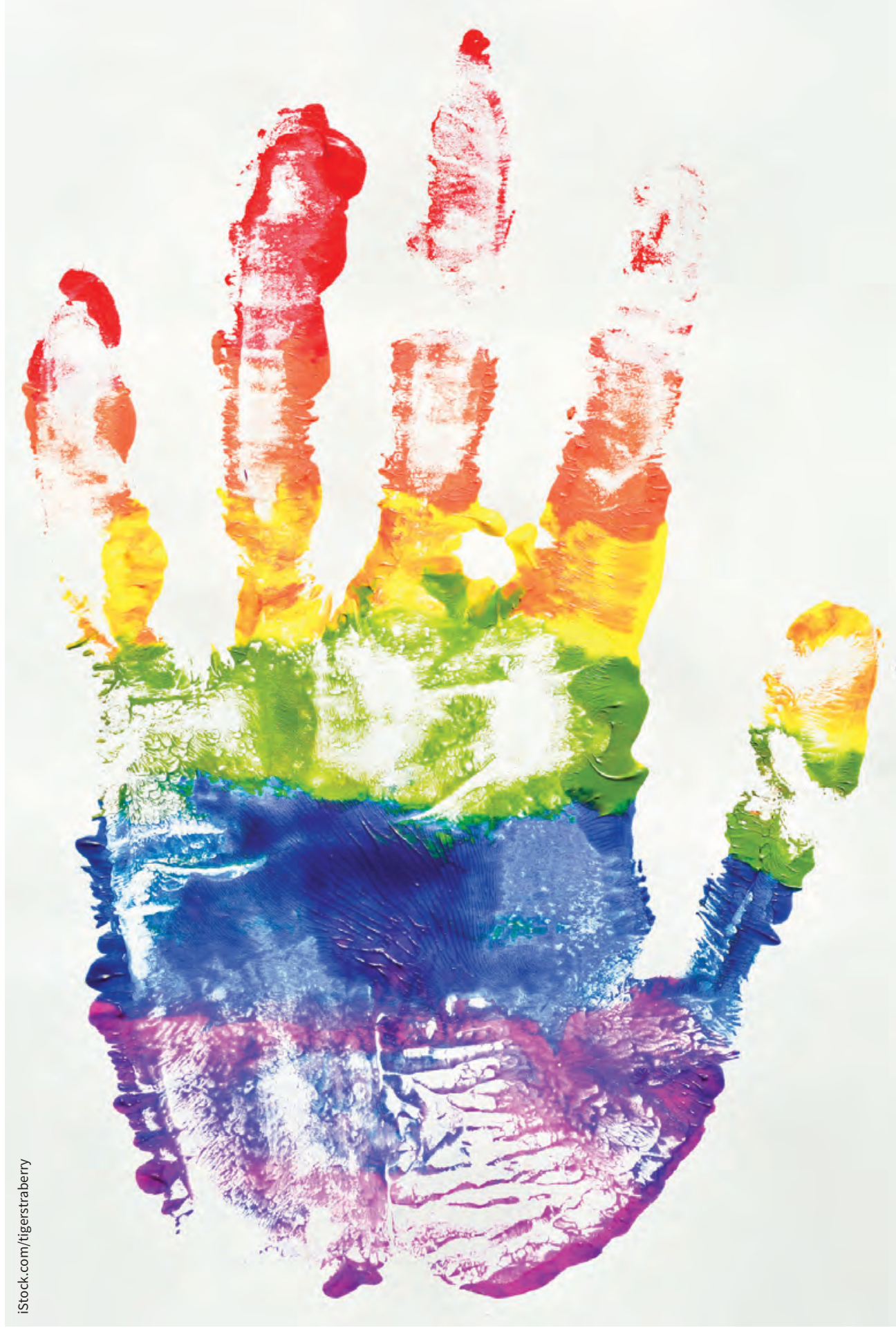


population; are you being safe?"; "If you're actually being safe, why did you even decide to come for STI testing? Only unsafe sex warrants STI testing."

Listening to these questions, I went from feeling responsible for my own health to feeling like a burden on this doctor and our health care system. Unspoken judgment radiated from the doctor's tone of voice and lingered in the dead, tense air that now filled the room. I knew these were important questions that needed to be asked, but with this delivery, I was now on the defensive. It felt like my answers were being doubted. I felt like I was being doubted. My identity as a health-literate medical student had vanished. I felt reduced to nothing more than a member of a "risky, unsafe population," a patient whose history might not be reliable enough. My palms grew slick once again.

As a trainee, I'm usually privy to the other side of this conversation, where patient histories can be questioned and assumptive interpretations may be made. I appreciate that these assumptions, often veiled as "clinical intuition," come from years of experience and not from a textbook, but assumptions don't develop without their shortcomings. I can now appreciate how it feels to be a patient who isn't trusted.

Have we lost compassion in our interactions, in favour of disease statistics and risk stratification? I felt like nothing more than a statistic that day, a statistic informing this doctor that my identity as a man who has sex with men (MSM) equated directly to risky sexual behaviour.
When the doctor asked if I had any other questions, I quickly shook my head and thanked them for their time, knowing I would never return, never seek care from someone who made me feel nothing more than a member of a risky, unsafe population.

\section{$\star \star \star$}

In health care, certain populations have been distinguished as "special," and are treated as such. The young, the old, those who use intravenous drugs, those who are pregnant, those who are Indigenous or LBGTQ2: the list is endless, filled with people who have been deemed different. We are taught to consider "high-risk populations" in medical school, but I have come to realize we may have fallen short in considering the people who make up these populations. "Populations" are filled with real people with real stories, but often we homogenize these people into a mysterious "them."

We are expected to commit to memory the many risk factors that predispose us to disease, and in memorizing these laundry lists, we have skimmed over the fact that these "risk factors" mistakenly include the identities that make each of us unique and complex human beings. I have been taught that my sexuality is apparently a "risk factor." Has this stereotypical teaching failed us? Is being gay truly a risk factor? We must clarify what exactly confers risk, and in this case, it's sexual practices, not sexual orientation.
The box that has been created for me is labelled "cisgender gay male." But people don't fit as neatly into these clear-cut boxes as we might assume. Although labels help us make sense of the world, often allowing us to navigate the complexity of society and sometimes seeming quite indispensable, if we're not careful, the assumptions that follow these labels may serve only to weaken the relationships we try so hard to cultivate with our patients.

I reflect on this experience as a relatively confident individual, as a medical student with high health literacy, whose first language is English, who is male. I am privileged that the hurt I have faced throughout my life has been limited - but I often reimagine the impact that these assumptions and this seemingly innocuous line of questioning could have had on someone with a different set of lived experiences. Although paternalism is no longer an acceptable approach to medicine, belief in the phrase "doctor knows best" is one that can be hard to shake. Small clinical moments may have bigger impacts for patients than we will ever know.

I am lucky to have left this encounter with nothing more than sweaty palms and a disappointing memory, but I share this story in the hope that we can think more critically about the individuals we serve, and less about the groups they might belong to.

\section{Justin Wei-Jia Lim BScH}

Faculty of Medicine, University of

Toronto, Toronto, Ont.

This article has been peer reviewed. 